This item was submitted to Loughborough's Research Repository by the author.

Items in Figshare are protected by copyright, with all rights reserved, unless otherwise indicated.

\title{
Nanostructred catalysts for photo-oxidation of endocrine disrupting chemicals
}

PLEASE CITE THE PUBLISHED VERSION

https://doi.org/10.1016/j.jphotochem.2018.05.010

PUBLISHER

(C) Elsevier

VERSION

AM (Accepted Manuscript)

\section{PUBLISHER STATEMENT}

This work is made available according to the conditions of the Creative Commons Attribution-NonCommercialNoDerivatives 4.0 International (CC BY-NC-ND 4.0) licence. Full details of this licence are available at: https://creativecommons.org/licenses/by-nc-nd/4.0/

\section{LICENCE}

CC BY-NC-ND 4.0

\section{REPOSITORY RECORD}

Baycan, Neval, and Gianluca Li Puma. 2019. "Nanostructred Catalysts for Photo-oxidation of Endocrine Disrupting Chemicals”. figshare. https://hdl.handle.net/2134/37023. 


\title{
Nanostructred Catalysts for Photo-oxidation of Endocrine Disrupting Chemicals
}

\author{
Neval Baycan', Gianluca Li Puma ${ }^{2}$ \\ ${ }^{1}$ Department of Environmental Engineering, Dokuz Eylul University, Izmir 35160, Turkey \\ ${ }^{2}$ Environmental Nanocatalysis \& Photoreaction Engineering, Department of Chemical \\ Engineering, Loughborough University, Loughborough LE1 1 3TU, United Kingdom. \\ Email: neval.baycan@deu.edu.tr; g.lipuma@,lboro.ac.uk
}

Removal of four Endocrine disrupting chemicals (EDCs) Estrone (E1), 17- $\beta$-estradiol (E2), Estriol (E3) and 17- $\alpha$-ethynylestradiol (EE2) were investigated using UV oxidation and combined with Nafion/iron catalyst. Immobilization of iron on the perfluorosulfonic polymer, Nafion ${ }^{\circledR}$, has been investigated as a carrier for the oxidation of pollutants by hydroxyl radicals (heterogenous photo-Fenton mechanism). However, the low surface area of Nafion, less than $0.2 \mathrm{~m}^{2} / \mathrm{g}$, usually results in low pollutant degradation rates. Sol-gel technology was used to produce a high surface area poly(dimethylsiloxane) (PDMS) modified Nafion/silica composite suitable for catalysis of the photo-Fenton reaction without significant leaching of iron. The incorporation of Nafion into silica greatly increases the accessibility of Nafion/iron loaded active site. PDMS reinforces the structure of silica and maintains the transparency of the composite, which is essential for efficient Photo-Fenton reactions. These composites were utilized for the decomposition of estrogens which are Estrone (E1), 17- $\beta$-estradiol (E2), Estriol (E3) and 17- $\alpha$-ethynylestradiol (EE2). In consequence, it is clear that the composite effectively catalyses the photo-Fenton reaction to remove estrone. The presence of iron through the use of the catalyst leads to rapid degradation of the estrone compared to just $\mathrm{H}_{2} \mathrm{O}_{2}$ and UV light alone. It was found that the addition of only $8.5 \mathrm{mg} / \mathrm{L} \mathrm{H}_{2} \mathrm{O}_{2}$ produced more than $\% 90$ conversion of estrogens within 60 minutes.

Keywords: EDC's, Nafion/iron catalyst, UV-oxidation. 


\section{Introduction}

Endocrine Disrupting Chemicals (EDCs) are environmental contaminants that interfere with endocrine system function [1]. Estrogens are a group of steroid chemicals functioning as the primary female sex hormone and are defined by their effects within the estrous cycle $[2,3]$. By imitating the hormonal system and altering the endocrine system function, estrogens act as EDCs and induce an adverse effect on the natural environment [4]. This impact is seen in animal populations due to the EDCs interference in reproductive and development cycles [5,6]. The past two decades have seen extensive research conducted highlighting how influential environmental chemicals, such as estrogens, are at interrupting the endocrine system causing reproductive abnormalities in wildlife [7]. Although natural hormones have always been present in the natural water system, the increasing use of both natural and artificial estrogens for both medicine (i.e. oral contraceptive pills, treatment of cancers and hormone replacement therapy) and animal farming have contributed to a substantial rise in their presence and subsequent pollution within the aquatic environment [8].

These EDCs are excreted and reach the aquatic environment mainly via Waste-Water Treatment Plants (WWTPs). WWTPs receive a broad range of molecules, including estrogens, that are not entirely removed during the treatment processes meaning that the discharges from WWTPs are considered to be a major source of estrogenic water pollution [1]. With worldwide reuse of surface water increasing and the potential for EDCs to bio-accumulate, the treatment and removal of estrogens from wastewater is becoming increasingly important [8].

Natural estrogens such as Estrone, Estriol and 17- $\beta$-estradiol and synthetic estrogens such as $17-\alpha$-ethynylestradiol (the main hormone within the oral contraceptive pill) are shown in Figure 1 and display the strongest estrogenic effects presenting a significant cause for concern $[5,7$, $8]$.

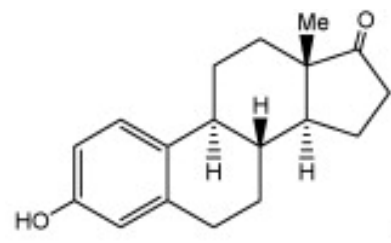

Estrone E1

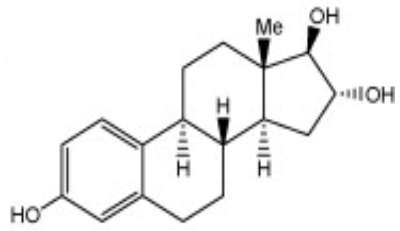

Estriol E3

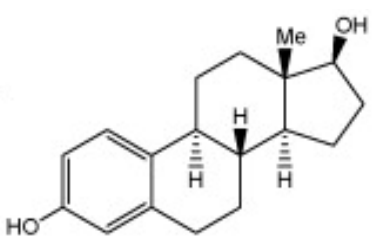

$17-\beta$-estradiol E2<smiles>C[C@]1(O)CC[C@H]2[C@@H]3CCc4cc(O)ccc4[C@H]3CC[C@]21N</smiles>

$17 \alpha$-ethynylestradiol EE2

\section{Figure 1: Molecular structures of estrogens}

The concern surrounding EDCs began in the 1980s when deformities in UK fish were discovered along stretches of river [9]. Abnormal male development in male alligators highlighted the reproductive hazards of EDCs to wildlife in the environment [10] and that EDC contamination of a wildlife population can potentially lower its reproductive success [11]. 
Research in both laboratories and the natural environment has shown that exposure to these EDCs can lead to disruption of reproduction and early development in aquatic wildlife $[12,13]$.

There are two main methods for improving the removal of steroid estrogens: to optimise existing technology, for example activated sludge treatment, or upgrade existing WWTPs with novel end of pipe technology, including Advanced Oxidation Processes (AOPs) [8, 14]. Research has taken place into membrane bioreactors, ozonation, membrane filtation and activated carbon adsorption $[8,15]$. However, these last two processes are highly energy and material intensive and currently cannot be effectively applied to a practical situation as they require relatively clean surface water or ground water with little natural organic matter [16].

AOPs and ozonation have been highlighted as more appropriate waste water treatment processes for pharmaceuticals, including contraceptive compounds, and for the oxidation of organic pollutants. These treatment processes can degrade pollutants through mineralisation or alter them to products that are less harmful to wildlife and the aquatic environment [24]. AOPs are characterized by the generation of hydroxyl radicals that involve different chemical agent combinations [6]. Example AOP combinations include $\mathrm{O}_{3} / \mathrm{H}_{2} \mathrm{O}_{2}, \mathrm{O}_{3} / \mathrm{UV}, \mathrm{O}_{3} / \mathrm{H}_{2} \mathrm{O}_{2} / \mathrm{UV}$, $\mathrm{H}_{2} \mathrm{O}_{2} / \mathrm{UV}$, Fenton $\left(\mathrm{Fe}^{2+} / \mathrm{H}_{2} \mathrm{O}_{2}\right)$, photo- and electro-Fenton, chelating agent assisted Fenton/photo-Fenton, heterogeneous photo oxidation using titanium dioxide $\left(\mathrm{TiO}_{2} / \mathrm{hv}\right), \gamma$ radiolysis, and sonolysis $[16,17]$.

This study will concentrate on the photo-Fenton reaction since Fenton-type processes have been found to be more effective than ozonation alone [16]. The Fenton reaction provides a powerful oxidant for contaminants through a reagent involving a mixture of ferrous iron (catalyst) and hydrogen peroxide (oxidising agent). The photo-Fenton process involves hydroxyl radical formation through photolysis of the hydrogen peroxide and Fenton reaction [18]. Given that the Fenton reaction is accelerated by light, the photo-Fenton reaction provides faster rates and potential for higher amounts of pollutant mineralisation [19]. This irradiation with UV light of the $\mathrm{Fe}^{3+}$ ions (produced by the Fenton reaction, as shown in equation [1] in the presence of $\mathrm{H}_{2} \mathrm{O}_{2}$ forms $\mathrm{Fe}^{2+}$ ions with a hydroxyl radical as shown in equation [2] [20, 21, 22 ]. A continuous cycle between the $\mathrm{Fe}^{2+}$ and $\mathrm{Fe}^{3+}$ species is generated.

The use of UV light in the presence of hydrogen peroxide and an iron based catalyst would eliminate the need for continuous addition of iron. Although the Photo-Fenton reaction is a popular choice for pollutant mineralisation, its application requires a $\mathrm{pH}$ of less than 4 otherwise a reduction in the amount of iron in the system occurs as it is precipitated out producing an iron sludge.

$$
\mathrm{Fe}^{2+}+\mathrm{H}_{2} \mathrm{O}_{2} \rightarrow \mathrm{Fe}^{3+}+\mathrm{OH}^{-}+\mathrm{HO}^{\bullet}
$$

Fenton Reaction

$$
\mathrm{Fe}^{3+}+\mathrm{H}_{2} \mathrm{O} \stackrel{\mathrm{UV}}{\longrightarrow} \mathrm{Fe}^{2+}+\mathrm{HO}^{\bullet}+\mathrm{H}^{+}
$$

Photo-reduction of $\mathrm{Fe}^{3+}$ ions

$$
\mathrm{HO}^{\bullet}+\mathrm{RH} \rightarrow \mathrm{H}_{2} \mathrm{O}+\mathrm{R}^{\bullet}
$$

Oxidation of organic species RH

The organic ion exchange resin, Nafion, has been tested as an immobilisation technique or carrier for the iron and is also known to catalyse a wide range of reactions [23, 24]. Nafion is chemically inert and a realistic option for use in WWTPs, unlike strong homogeneous acid 
catalysts $[24,25]$. Its resistance to oxidative conditions and ability to form stable complexes with both $\mathrm{Fe}^{2+}$ and $\mathrm{Fe}^{3+}$ prevents precipitation (leading to the iron sludge) at $\mathrm{pHs}$ higher than 4 and allows the Fenton reaction to occur at $\mathrm{pH} 7$ (closer to that of WWTPs). Nafion is also transparent for UV radiation and is therefore suitable for use with the photo-Fenton reaction [26].

One disadvantage of Nafion is its low surface area. Several studies have shown the success of developing a new kind of solid Nafion catalyst by entrapping the resin particles in a highly porous silica matrix [23, 25, 27, 28]. The use of silica provides a large inter-surface for the catalytic reaction and better accessibility of the catalytically active acid sites by making the catalyst more porous [23, 29].

A previous study showed that using the sol-gel technique to produce the catalyst is most effective at optimising the materials listed above to create a catalyst suitable for xenobiotic chemicals with readily available active sites [25]. The sol-gel method used here follows previous studies [24, 28 ] and employs a gelation agent, the hydrolysis and polycondensation of alkoxides to form the gel, followed by aging and drying to give the solid catalyst. The twostep process reported by Kim et al. [28] refers to the acidic and alkaline environments being separated to allow more control of the reflux reaction [24]. PDMS acts as the gelation agent and has previously shown to add toughness and flexibility to the catalyst [30] by having a positive effect on the structural stability.

In this study, sol-gel technology will be used to produce a high surface area PDMS modified Nafion/silica composite suitable for catalysis of the photo-Fenton reaction without significant leaching of iron. One aim of this research is to develop a catalyst that did not produce an iron sludge from the photo-Fenton AOP and to see if that is reproducible for use in wastewater treatment. Therefore, the catalysts apply to degrade Estrone, 17- $\beta$-estradiol, Estriol, and $17 \alpha-$ ethynylestradiol.

\section{Materials and Methods}

\subsection{Materials}

All chemicals were used as received without further purification. The chemical reagents used for synthesis of the poly(dimethylsiloxane) modified Nafion/silica composite: Tetraethoxysilane (TEOS) (Fisher Scientific) was used as a precursor of silica. Hydroxy terminated poly(dimethylsiloxane) (PDMS) (Sigma-Aldrich) with average molecular weight of 550 was used as a structure modifier, elastomer. Nafion oligomer (5 wt. \% in lower aliphatic alcohols and water, contains 15-20\% water) (Sigma-Aldrich) was used as an iron species carrier for Photo-Fenton reaction. Iron (II) chloride $\left(\mathrm{FeCl}_{2} \cdot 4 \mathrm{H}_{2} \mathrm{O}\right)$ (Laboratory FSA Supplies) was used as a source of iron species. Isopropanol (IPA) and tetrahydrofuran (THF) were used as mutual solvents for dissolving TESO, PDMS and Nafion polymers. Hydrochloric acid ( $\mathrm{HCl})$ and sodium hydroxide $(\mathrm{NaOH})$ were used for catalysing hydrolysis and condensation, respectively.

Estrone (E1), 17 -estradiol (E2), estriol (E3) (purity $\geq 97 \%$ ) and 17- $\alpha$-ethynylestradiol (EE2) (purity $\geq 98 \%$ ) were obtained from Sigma-Aldrich. For the HPLC analyses acetonitrile (E Chromasolv ${ }^{\circledR}$ for HPLC, far UV) was supplied by Riedel-de Haën. Ultra high purity water for all experiments and analyses was produced by a NANOpure Diamond UV water purification 
system that provides bacteria free water of $18.2 \Omega \mathrm{cm}^{-1}$ resistivity with less than $1 \mathrm{ppb}$ total organic carbon.

\subsubsection{Synthesis of Catalyst}

The uses of each chemical in the production of the catalyst and its source are listed below: Hydroxyl terminated Polydimethylsiloxane (PDMS) (average Mr 550): Used as a structure modifier. Tetraethylorthosilicate (TEOS): Used as a soluble silica precursor/to form silica in the catalyst [23, 31]. Tetrahydrofuran (THF) and Isopropanol/propan-2-ol (IPA): Mutual solvents for dissolving the polymers Nafion, PDMS and TEOS. Hydrochloric Acid (HCl): Catalysed hydrolysis Sodium Hydroxide $(\mathrm{NaOH})$ : Catalysed condensation leading to gelation [25]. Anhydrous iron chloride $\left(\mathrm{FeCl}_{2}\right)$ : A source of iron species. Nafion: To support the iron species and act as an iron species carrier for the Photo-Fenton reaction [31]. All the chemicals required for the catalyst synthesis were used as received. The following method and molar ratios were based on the previous work to produce a poly(dimethysiloxane) modified Nafion/silica sol-gel composite catalyst for the removal of pesticides and the degradation of azo-indigo carmine solution. Fixed molar ratio of TEOS:THF:IPA: $\mathrm{HCl}=1: 1: 4: 0.03, \mathrm{SiO}_{2}: \mathrm{PDMS}=9: 1$, Nafion:Fe $=1: 1.5, \mathrm{NaOH}: \mathrm{THF}=0.15: 1$ and TEOS:THF $: \mathrm{H}_{2} \mathrm{O}=1: 1: 3$ were used.

The PDMS was dissolved in THF, then mixed with TEOS and heated up to $30^{\circ} \mathrm{C}$ for 5 minutes. Water, $1 \mathrm{M} \mathrm{HCl}$ and IPA are added and the resulting solution is then bought to reflux for 60 minutes at $30^{\circ} \mathrm{C}$. Anhydrous $\mathrm{FeCl}_{2}$ was mixed with $5 \mathrm{wt}$. \% Nafion resin solution at $30^{\circ} \mathrm{C}$ for 5 minutes. An ultrasonic treatment was then performed on this solution for 30 minutes to ensure uniform dispersion of the Nafion polymer and iron. The refluxed solution was added to the ultrasonic treatment solution. This was continuously stirred whilst $5 \mathrm{M} \mathrm{NaOH}$ solution was added drop by drop. The mixture soon became an off-white colour and gelled to form a solid mass. This was transferred to a watch glass and left in a fume cupboard overnight where it dried and cracked to form uneven sized, solid pellets. This was then dried in a Memmert fresh air oven at a temperature of $50^{\circ} \mathrm{C}$ for one hour, then at $100^{\circ} \mathrm{C}$ for another hour to remove any excess solvents. The catalyst was ground to powder before being used. Scanning Electron Microscope technology (SEM) and was used to analyse the catalyst morphology. EnergyDispersive X-ray Spectroscopy (EDX) used for elemental analysis of the sample and chemical characterisation.

\subsection{Experimental procedures}

Stock solutions of E1, E2, EE2 and E3 in acetonitrile at $10 \mathrm{mg} / \mathrm{L}$ were freshly prepared due to the poor solubility of the estrogens in water. They were diluted with ultrapure water to the desired concentration required for each experiment and or analysis. Estrogen experiments took place at natural $\mathrm{pH}(\approx 4.9)$. Initially $0.1 \mathrm{mg} / \mathrm{L}$ estrogens were used. The amount of catalyst and $\mathrm{H}_{2} \mathrm{O}_{2}$ were varied during experiments. Samples were taken at appropriate time intervals, solid phase extraction was used to concentrate and purify the samples so high performance liquid chromatography analysis could be used to quantify the amount of estrogen present calibration curves.

The photocatalytic reactions were set up, as shown in Figure 2, in a $100 \mathrm{ml}$ reaction volume with a $2 \mathrm{~cm}$ stirrer. Three Phillips UV lamps were used as a light source the oxidation reaction, the measured intensities are shown in

Table 1. The UV lamps were only turned on desired of Hydrogen peroxide $\left(\mathrm{H}_{2} \mathrm{O}_{2}\right)$ had been added. 
Table 1. UV intensity

\begin{tabular}{|l|l|l|}
\hline Position & $\begin{array}{l}\text { UVA intensity } \\
\left(\mathrm{W} / \mathrm{m}^{2}\right)\end{array}$ & $\begin{array}{l}\text { UVC intensity } \\
\left(\mathrm{W} / \mathrm{m}^{2}\right)\end{array}$ \\
\hline 1 & 33.4 & 32 \\
\hline 2 & 19.45 & 26 \\
\hline
\end{tabular}
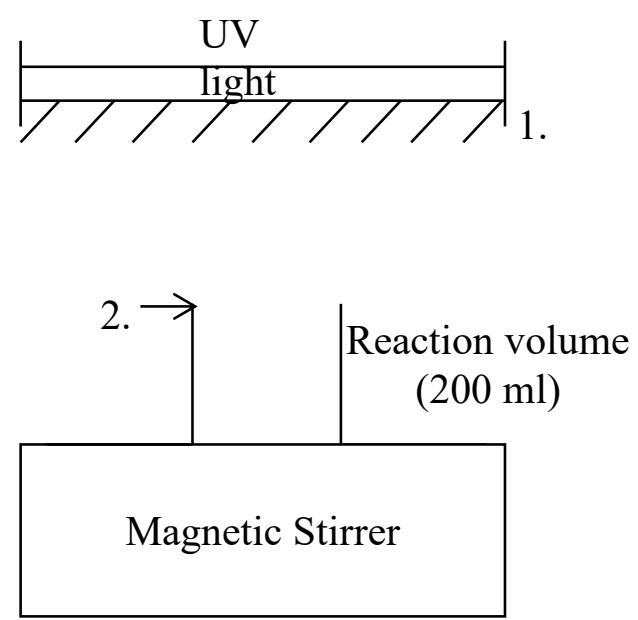

Figure 2: Experimental set-up

\subsection{Analytical Techniques}

\subsubsection{Solid Phase Extraction (SPE)}

The estrogen sample was filtered to remove any catalyst through $0.22 \mu \mathrm{m}, 33 \mathrm{~mm}$ Millipore GP filter units. The Oasis ${ }^{\circledR}$ SPE Method for estrogens in river water (endocrine disrupters) reported by Waters was used and is shown in appendix B. OASIS ${ }^{\circledR}$ HLB, 3 cc, $200 \mathrm{mg}$ cartridges were connected to Supelco visiprep ${ }^{\mathrm{TM}}$ vacuum manifold system with a Gast vacuum pump, to increase the solvent flow rate via the valves. The conditioning and wash steps described by Li Puma et al. [5] were followed. The cartridges were conditioned (all solvent drawn through cartridges) with $3 \mathrm{~mL}$ methyl-tert-butyl-ether (MTBE). They were then washed with $3 \mathrm{~mL}$ methanol, followed by $3 \mathrm{~mL}$ water. $10 \mathrm{~mL}$ of sample was loaded to the cartridges, the flowrate was then adjusted to one drop per second, to ensure the estrogens had as much contact time with the cartridges as possible, and a second wash step of $3 \mathrm{~mL} 5 \%$ methanol in $\mathrm{H}_{2} \mathrm{O}$ took place. The cartridges were then left to dry overnight. Elution into clean test tubes with $6 \mathrm{~mL} 10 \%$ methanol in MTBE took then occurred. This elute was evaporated to dryness with nitrogen gas. After being increased to a final volume of $1 \mathrm{~mL}$ by $43 \%$ acetonitrile, $57 \%$ water, this was transferred to HPLC vials for analysis.

\subsubsection{Iron detection}

1,10-Phenanthroline: Reacts with ferrous ions to form a red complex to allow colorimetric detection as a method of determination of iron [32, 33]. Hydroxylamine hydrochloride: The iron must be in a ferrous state; therefore hydroxylamine hydrochloride is used as a reducing agent. Sodium acetate was used to control $\mathrm{pH}$. Iron leaching from the composite was determined by colorimetric detection using the spectrophotometer at wavelength of $508 \mathrm{~nm} .1 \mathrm{~mL}$ hydroxylamine hydrochloride was added to $25 \mathrm{~mL}$ solution samples that had been filtered through a Millipore $0.22 \mu \mathrm{m}$ filter. $10 \mathrm{~mL}$ of 1,10-phenanthroline was reacted with the samples 
to form a red complex and then $8 \mathrm{~mL}$ sodium acetate added to each. Each sample was diluted to $100 \mathrm{~mL}$ with distilled water and left for 10 minutes. The absorbance was then recorded and any iron concentration calculated from a calibration curve.

\subsubsection{High Performance Liquid Chromatography}

All the HPLC solvents were vacuum filtered prior to use. HPLC system (Agilent 1100 series) comprised a diode array detector a mobile phase degassing unit and an autosampler. HPLC was used to analyse the concentration of estrogen compounds and to track their degradation. The HPLC system used was a SUPELCOSIL ${ }^{\mathrm{TM}}$ LC-8 58297-53777-05 $250 \mathrm{~mm} \times 4.6 \mathrm{~mm}$ x $5 \mu \mathrm{m}$ column and had an injection volume of $10 \mu \mathrm{l}$. The conditions were: the mobile phase comprised $43 \%$ Water, $57 \%$ Acetonitrile; the flow rate was set at $1 \mathrm{~mL} / \mathrm{min}$; column temperature of $15^{\circ} \mathrm{C}$ and detector wavelengths 200 and $280 \mathrm{~nm}$. These parameters followed those used in multiple studies using this group of estrogens [5].

\subsection{4 $\mathrm{H}_{2} \mathrm{O}_{2}$ analysis}

The concentration of any remaining $\mathrm{H}_{2} \mathrm{O}_{2}$ was measured using Quantofix peroxide 25 test sticks for $0.5-25 \mathrm{mg} / 1 \mathrm{H}_{2} \mathrm{O}_{2}$, sourced from Sigma Aldrich, UK.

\section{Results and Discussions}

In the first part of the experimental study the aim was to determine characterisations of the catalyst. For this reason SEM, EDX and BET surface area and Zeta potential determinations was done.

\subsection{Catalyst Characterisation Results}

During catalyst preparation, the solution remained colourless whilst PDMS, TEOS, IPA and THF were mixed together but this clarity decreased after the addition of water due to the hydrophobic properties of both PDMS and TEOS. At the end point of the hydrolysis of TEOS however, the mixture was colourless/clear again. A brown precipitate formed when the Nafion resin solution was added to the $\mathrm{FeCl}_{2}$ and after addition of this to the colourless solution, a yellowish mixture formed. Gelation began immediately after the gelating agent $(\mathrm{NaOH})$ was added, forming a hard gel. After drying overnight and thermal treatment, a powdery composite that cracked into pellets, shown in Figure 3 and Figure 4, was formed. Following the method described earlier, approximately $12 \mathrm{~g}$ (ambient weight) of catalyst was formed each time. The BET surface area of the catalyst is $95 \mathrm{~m}^{2} / \mathrm{g}$. According to zeta potential measurements the zeta value of the catalyst is -52 at $\mathrm{pH} 7$.
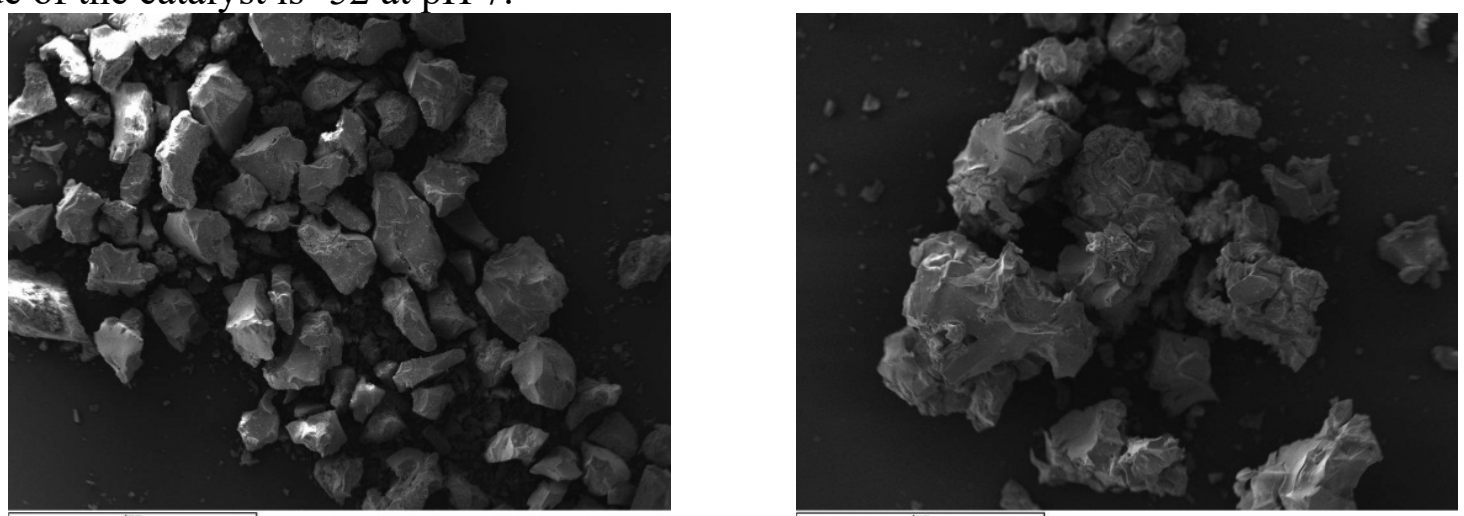
SEM technology showed the catalyst's characteristics and surface morphology. The catalyst was found to be very porous but did not have a very uniform morphology as can be seen by the 'areas of damage' apparent from Figure 5 and Figure 6.

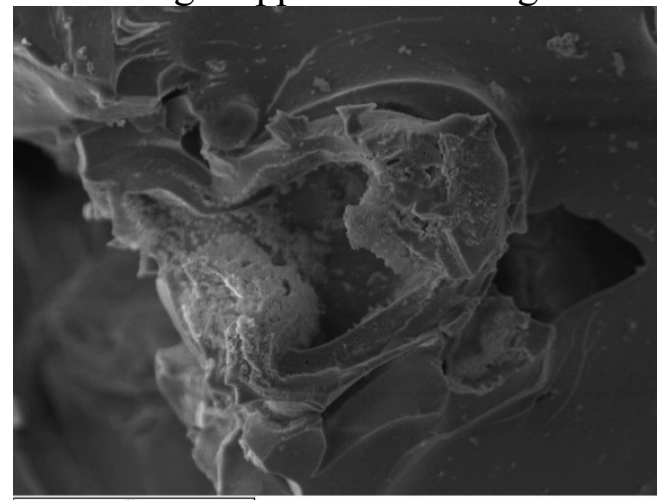

Figure 5: SEM image of damage area on catalyst

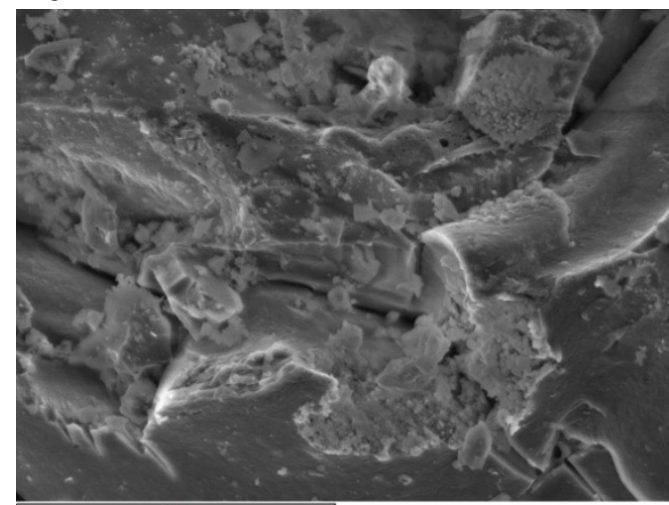

Figure 6: Higher resolution SEM image of damage area

The EDX elemental analysis, seen in Table 2, estimates the weight percentage of iron in the catalyst. Although the percentage weights are extremely low, the composite was fixed at $4 \mathrm{wt} \%$ Nafion; the theoretical value is only $0.15 \%$ for the iron fully loaded on the Nafion oligomer in composite. The variance and lack of iron in one spectrum could be due to the iron forming as clusters on the silica supported Nafion matrix.

Table 2. EDX results

\begin{tabular}{|l|l|l|l|l|l|l|}
\hline & \multicolumn{2}{|c|}{ Spectrum 1 } & \multicolumn{2}{c|}{ Spectrum 2 } & \multicolumn{2}{c|}{ Spectrum 3 } \\
\hline Element & \multicolumn{1}{|c|}{$\mathrm{Wt} \%$} & $\sigma$ & \multicolumn{1}{c|}{$\mathrm{Wt}^{2} \%$} & $\sigma$ & $\mathrm{Wt} \%$ & $\sigma$ \\
\hline $\mathrm{O}$ & 46.5 & 0.4 & 51.9 & 0.4 & 49.6 & 0.5 \\
\hline $\mathrm{Si}$ & 27.7 & 0.2 & 24.6 & 0.2 & 25.8 & 0.3 \\
\hline $\mathrm{C}$ & 14.6 & 0.5 & 11.9 & 0.6 & 15.3 & 0.6 \\
\hline $\mathrm{F}$ & 5.7 & 0.2 & 2.7 & 0.1 & 4.1 & 0.3 \\
\hline $\mathrm{Na}$ & 3.9 & 0.1 & 7.8 & 0.0 & 3.1 & 0.1 \\
\hline $\mathrm{Cl}$ & 1.4 & 0.0 & 1.1 & 0.0 & 2.0 & 0.1 \\
\hline $\mathrm{Fe}$ & 0.1 & 0.0 & - & - & 0.2 & 0.1 \\
\hline
\end{tabular}

\subsection{Estrogens Experiments}

\subsubsection{Calibration curves}

The analyzes retention times were $3.7 \mathrm{~min}$ for E3, $4.9 \mathrm{~min}$ for E2, $5.5 \mathrm{~min}$ for EE2 and $6.6 \mathrm{~min}$ for E1. Calibration of the HPLC chromatographic peaks against standards of the estrogens in acetonitrile resulted in a linear response in the range of concentrations investigated $(0.01-$ $0.1 \mathrm{mg} / \mathrm{L})$. The smallest quantifiable chromatographic peak after SPE corresponded to approximately $0.01 \mathrm{mg} / \mathrm{L}$ for each estrogens. Identification of the sample was done by identifying the retention time of standard solutions. All samples injected and analyzed three times and mean values of the results were given. 
Calibration curves were plotted from integrating the peaks from chromatographs of five known concentrations of estrogens. $\mathrm{R}^{2}$ values show the accuracy of the calibration curve and therefore their reliability. The high correlation coefficient value of all the calibration curves suggests that the SPE followed by HPLC analysis is an accurate method of quantifying estrogen concentrations. $\mathrm{R}^{2}$ was 0.9931 for E1, 0.9951 for E2, 0.9845 for EE2 and 0.9813 for E3.

\subsubsection{Degradation of EDCs}

Initial experiments were done to confirm that the composite was catalysing the photo-Fenton reaction. A series of experiments were conducted to see the effect of catalyst for oxidation and adsorption. These experiments were carried out in the presence and absence of UV light. The adsorption effect was limited to 5\%. All show minimal change confirming that without the presence of $\mathrm{H}_{2} \mathrm{O}_{2}$ and UV light, the composite does not catalyse the photo-Fenton reaction and degrade the E1. Final experiment evaluated the ability of $\mathrm{H}_{2} \mathrm{O}_{2}$ to degrade E1 which was negligible compared to with the Fenton catalyst, possibly due to the high oxidation potential of the hydroxyl radicals formed due to the iron present in the catalyst. From the results, it is clear that the composite effectively catalyses the photo-Fenton reaction to remove estrogens. The presence of iron through the use of the catalyst leads to rapid degradation of the estrogens compared to just $\mathrm{H}_{2} \mathrm{O}_{2}$ and UV light alone [34].

At the beginning of the degradation studies of estrogens, it was tried to find out the effects of UVA and UVC. The rates of photocatalytic degradation of the estrogens under irradiation of $0.1 \mathrm{~g}$ catalyst and $8.5 \mathrm{mg} / \mathrm{L} \mathrm{H}_{2} \mathrm{O}_{2}$ with UVC were much higher than the rates under UVA photolysis (Figure 7). Therefore, UVC radiations were chosen for further studies. The faster degradation of the estrogens under UVC irradiation can be explained by their much stronger absorption of photons in the UVC region of the electromagnetic spectrum [5]. These experiments clearly demonstrated the limitation of only UV-based oxidation processes, where absorption of light is the most important step to initiate the photolysis and subsequent photooxidation [35].

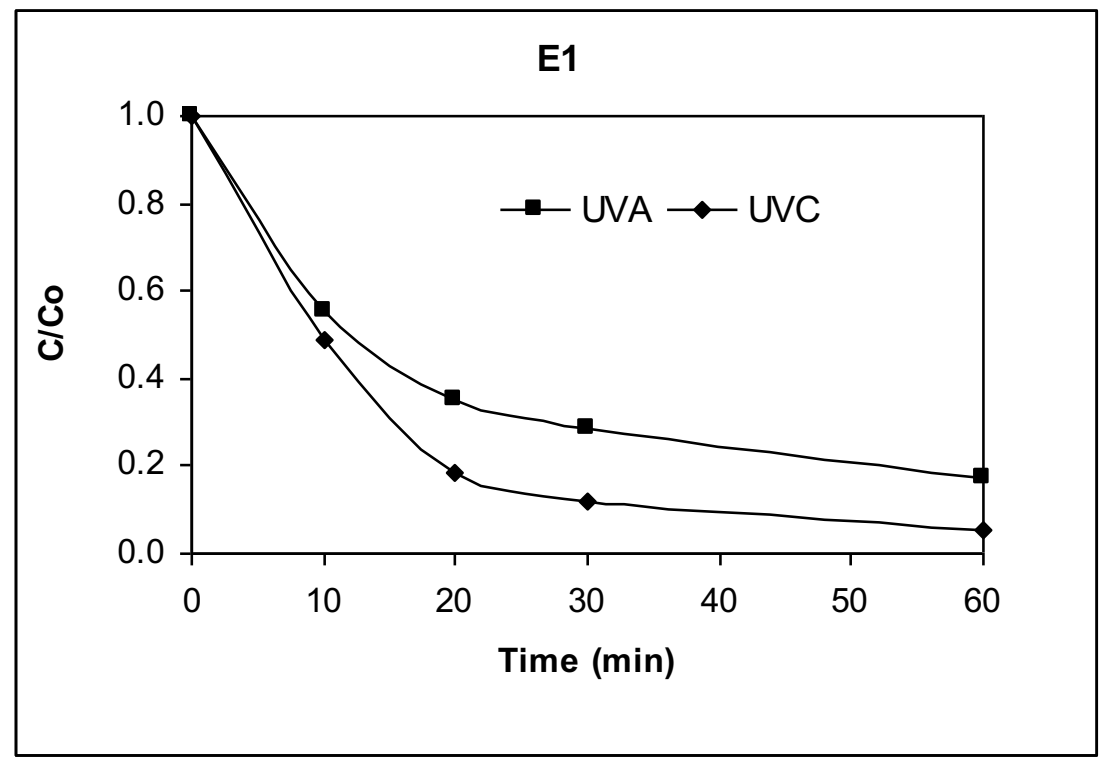

Figure 7: Degradation of 0.1mg/L E1 under UVA and UVC lights

The rapid rate of degradation can be clearly seen showing that the composite effectively catalyses the photo-Fenton reaction to remove estrone. There was no significant difference 
between $0.1 \mathrm{~g}$ and $0.5 \mathrm{~g}$ catalyst concentrations (Figure 8) on the removal efficiency. For this reason $0.1 \mathrm{~g}$ catalyst concentration was chosen as the optimum catalyst concentrations. It is clear from the similar rates of degradation that in this situation, the amount of catalyst is not the limiting factor.

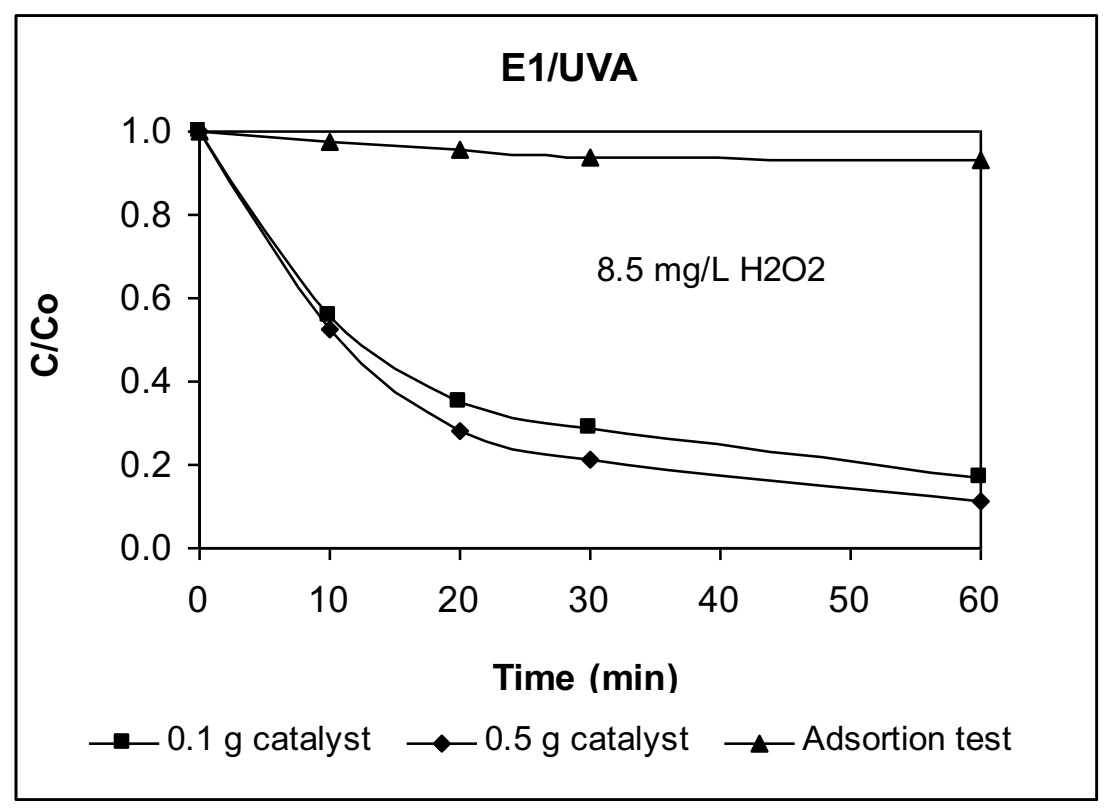

Figure 8: Rate of degradation of $\mathrm{E} 1\left(\mathrm{C}_{0}=0.1 \mathrm{mg} / \mathrm{L}\right)$

Iron leaching analysis were applied after each experimental studies. Experiments shows that the leached iron is a very minimal/limited amount, the small absorbance values measured and the fact that the catalyst was able to be re-used more than once led to the conclusion that a minimal amount of iron leaches. The same experiments were repeated three times in succession to determine the availability of the catalyst and effects on the catalyst yield were observed. The catalyst used during these three experiments was filtered, dried and reused. At the end of the third experiment, the treatment yield was found to be reduced by about $20 \%$. Non-quantifiable methods confirmed that iron leaching did occur, however, even extremely small amounts of iron are able to produce hydroxyl radicals in the presence $\mathrm{H}_{2} \mathrm{O}_{2}$ [36] and using the calibration curve the highest iron leaching quantity was $0.4 \mathrm{mg} / \mathrm{l}$. These experiments highlighted the improved method for producing a more effective catalyst due to much faster degradation rates. The reaction is not linear and follows previous research [5], although the degradation experienced with this catalyst is much faster. 


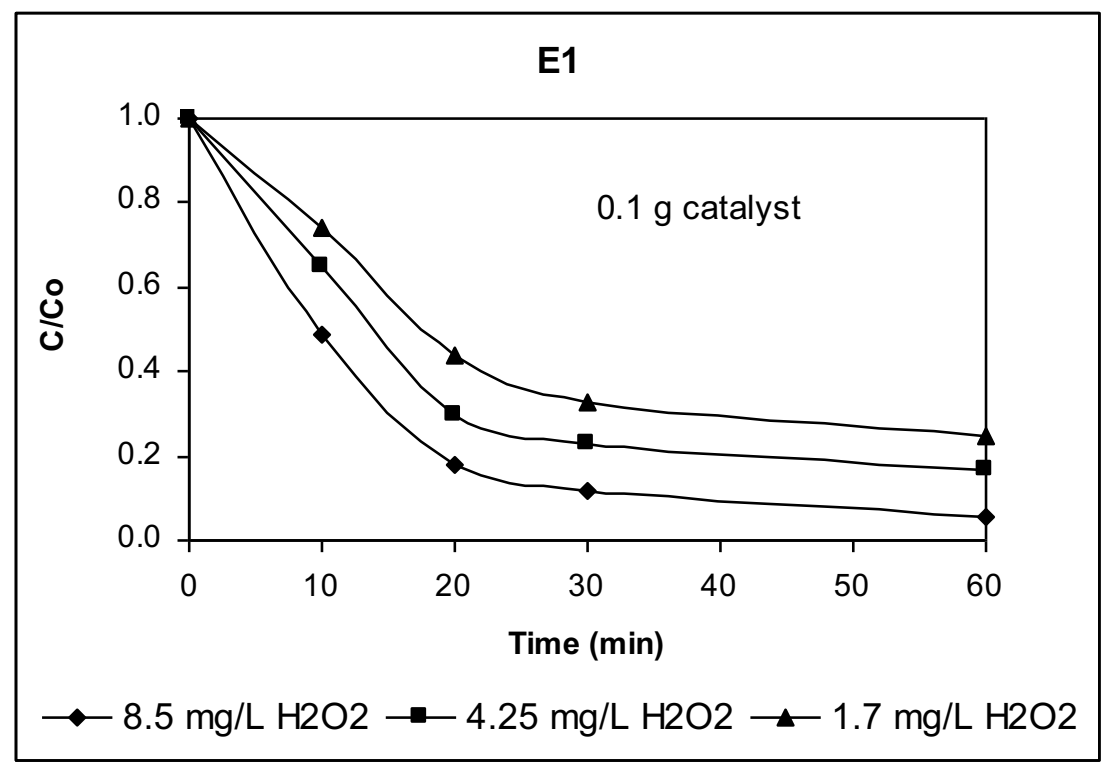

Figure 9: Degradation changes of $\mathrm{E} 1$ for different $\mathrm{H}_{2} \mathrm{O}_{2}$ concentrations under UVC light

In order to determine the effect of $\mathrm{H}_{2} \mathrm{O}_{2}$ on estrogen removal efficiencies three different $\mathrm{H}_{2} \mathrm{O}_{2}$ concentrations were used with the addition of constant catalysts concentration, $0.1 \mathrm{~g}$. Maximum E1 removal efficiency was obtained as $95 \%$ in 60 min at a $\mathrm{H}_{2} \mathrm{O}_{2}$ concentration of $8.5 \mathrm{mg} / \mathrm{L}$ and a catalyst concentration of $0.1 \mathrm{~g}$ under UCV light. Figure 9 shows the degradation rates changes of $\mathrm{E} 1$ for different $\mathrm{H}_{2} \mathrm{O}_{2}$ concentrations. The removal efficiency of $\mathrm{E} 1$ was only $70 \%$ with addition of $1.7 \mathrm{mg} / \mathrm{L} \mathrm{H}_{2} \mathrm{O}_{2}$. It was obvious that the $\mathrm{H}_{2} \mathrm{O}_{2}$ concentration is very effective on the removal of estrogens. The maximum $\mathrm{E} 2$ removal efficiency also obtained with the addition of the maximum $\mathrm{H}_{2} \mathrm{O}_{2}$ concentration $(8.5 \mathrm{mg} / \mathrm{L}$ ) (Figure 10).

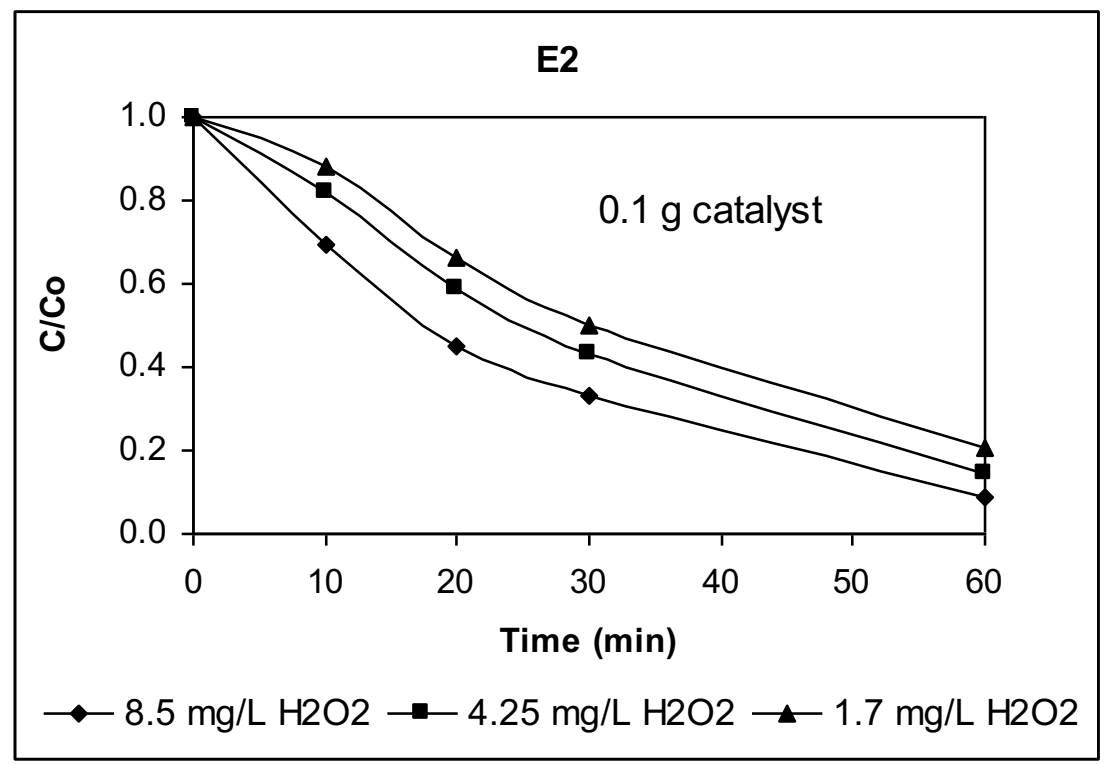

Figure 10: Degradation changes of $\mathrm{E} 2$ for different $\mathrm{H}_{2} \mathrm{O}_{2}$ concentrations under UVC light

Figure 11 shows the degradation changes of EE2 with the addition of different $\mathrm{H}_{2} \mathrm{O}_{2}$ concentrations. The effect of the $\mathrm{H}_{2} \mathrm{O}_{2}$ concentrations on the removal efficiency of EE2 was higher than the E1 and E2. 98\% removal efficiency was obtained with the addition of the 8.5 $\mathrm{mg} / \mathrm{L} \mathrm{H}_{2} \mathrm{O}_{2}$. 


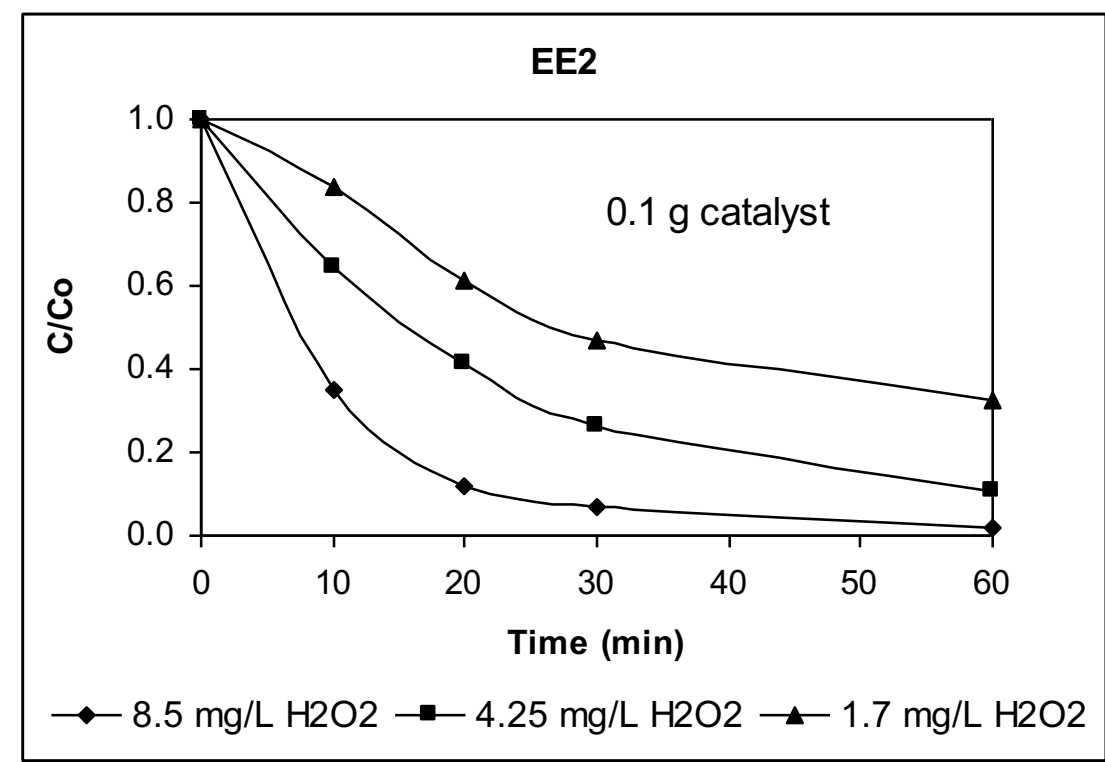

Figure 11: Degradation changes of EE2 for different $\mathrm{H}_{2} \mathrm{O}_{2}$ concentrations under UVC light

The maximum removal efficiency of E3 (Figure 12) was only $70 \%$ with the highest $\mathrm{H}_{2} \mathrm{O}_{2}$ addition. The removal efficiency of E3 is less than other estrogens. Similarly Li Puma et.al [5] was found that the degradation sequence with a multi component solution of estrogens, follows the sequence E1 $>$ EE2 $>$ E2 $>$ E3.

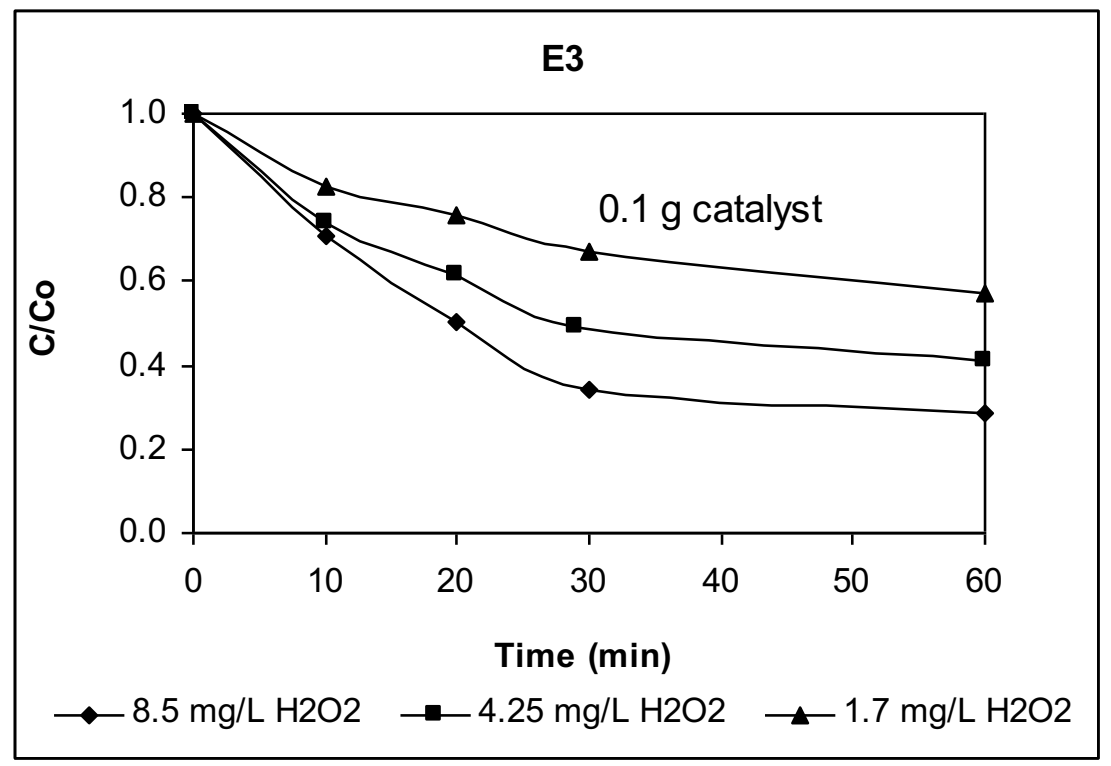

Figure 12: Degradation changes of E3 for different $\mathrm{H}_{2} \mathrm{O}_{2}$ concentrations under UVC light

\subsubsection{Degradation of Mixture of Estrogens}

There is a tendency to focus solely on the primary individual usually involves multiple chemicals in EDC mixtures [37]. Mixture constituents can act via common modes of action, or by a variety of signal transduction pathways which might crosstalk or produce other matrix effects. "Combination effects" occur when synthetic EDCs interact with each other, or with 
natural compounds in the environment and in the body, and they can have additive, synergistic or attenuative potential. When combined in a mixture, individual chemicals can contribute to toxicity in direct proportion to their potency and concentration, even if they are each present at a concentration below their individual effect thresholds. This phenomenon is termed "something from nothing". Experimental evidence shows that the cumulative impact of EDCs remains poorly understood, in part because traditional dose-response testing neglects the potential mixture effects not seen in single chemical testing. Only a better understanding of real-life combined exposures can determine whether risk is amplified by exposure to mixtures. For this reason to see the combination effects on EDC oxidation, initial concentration of 0.1 $\mathrm{mg} / \mathrm{L}$ of EDCs were mixed and oxidised under UVC light.

As can be seen from Figure 13 there was no significance effects of the mixture of estrogens. The maximum removal efficiency obtained for E2 and it was $92 \%$ for the mixture of EDCs. These results are much better than Li-Puma [5] obtained before.

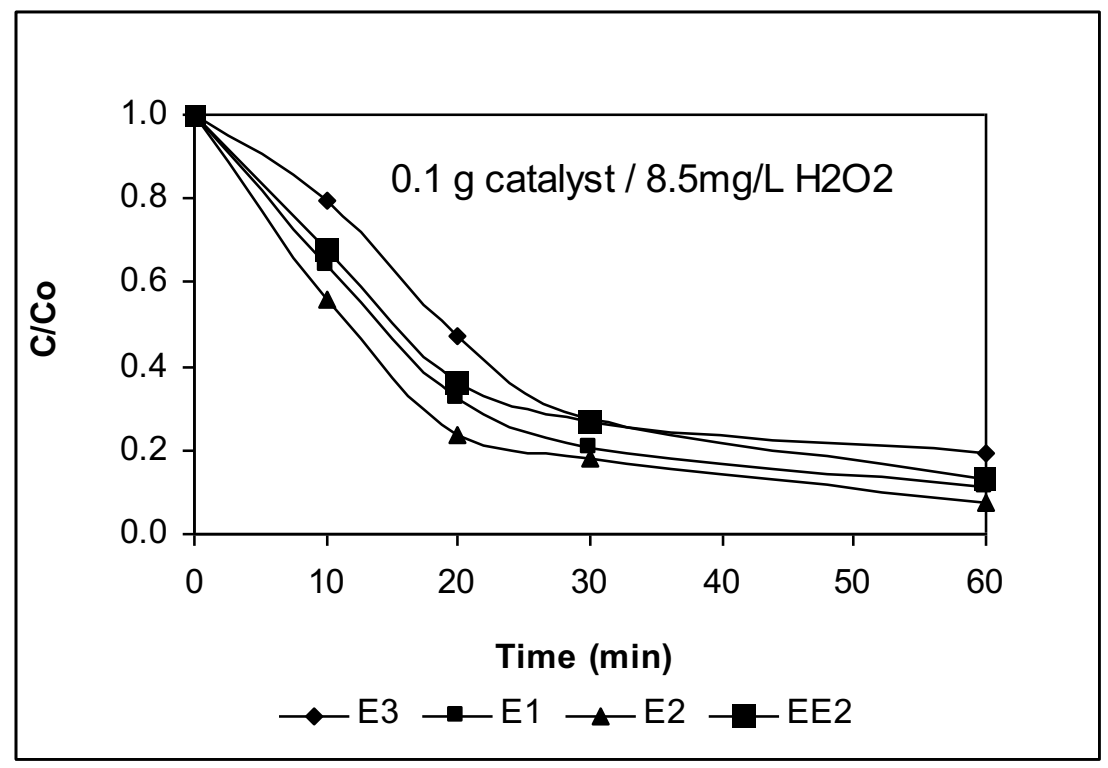

Figure 13: Degradation changes of mixed estrogens under UVC light

\subsubsection{Effect of Humic Acid}

Natural organic matter (NOM) is a complex heterogeneous aggregate of organic compounds defined as decaying material from plants, animals and their degradation products in terrestrial environments as well as in aquatic systems. It has been known that NOM shows important impacts on energy and carbon dynamics [38]. Dissolved organic carbon (DOC) components in aquatic systems have display high reactivity and influence ecosystem functions over many biogeochemical reactions, with metal ions and hydrous metal oxides. In aquatic system, one of the natural DOC material is Humic substances (HSs) mainly humic acids (HAs). Natural Organic Meters has known as an oxidant scavenger. Hence it was determined the effect of the HAs.

From the literature [38] the humic acid concentrations were chosen as 10, 20, 30, 40 and 50 $\mathrm{mg} / \mathrm{L}$. But even if with the addition of $10 \mathrm{mg} / \mathrm{L}$ humic acid to the mixture of estrogens the removal efficiencies decreased approximately 10-15\% (Figure 14). And also, UV $\mathrm{UV}_{254}$ and Color 436 were measured to determine the removal efficiency of the humic acid. $70 \%$ Color 436 and $50 \% \mathrm{UV}_{254}$ removal efficiencies were obtained. To further reduce parent compounds and oxidation by-products, biological post-filtration (sand filtration or activated carbon filtration) 
can be considered [39]. It was reported that when UVC was combined with $\mathrm{H}_{2} \mathrm{O}_{2}$, natural organic matter could not be mineralized [37]. For some limited number of experiments TOC was measured after a long experimental time. It was seen that for ozonation $(1.31 \mathrm{mg} / \mathrm{L}), \mathrm{TOC}$ removal was about $85 \%$ after $500 \mathrm{~min}(8.33 \mathrm{~h})$, while for $\mathrm{UV} / \mathrm{H}_{2} \mathrm{O}_{2}$ it was only $65 \%$ for the same time [42].

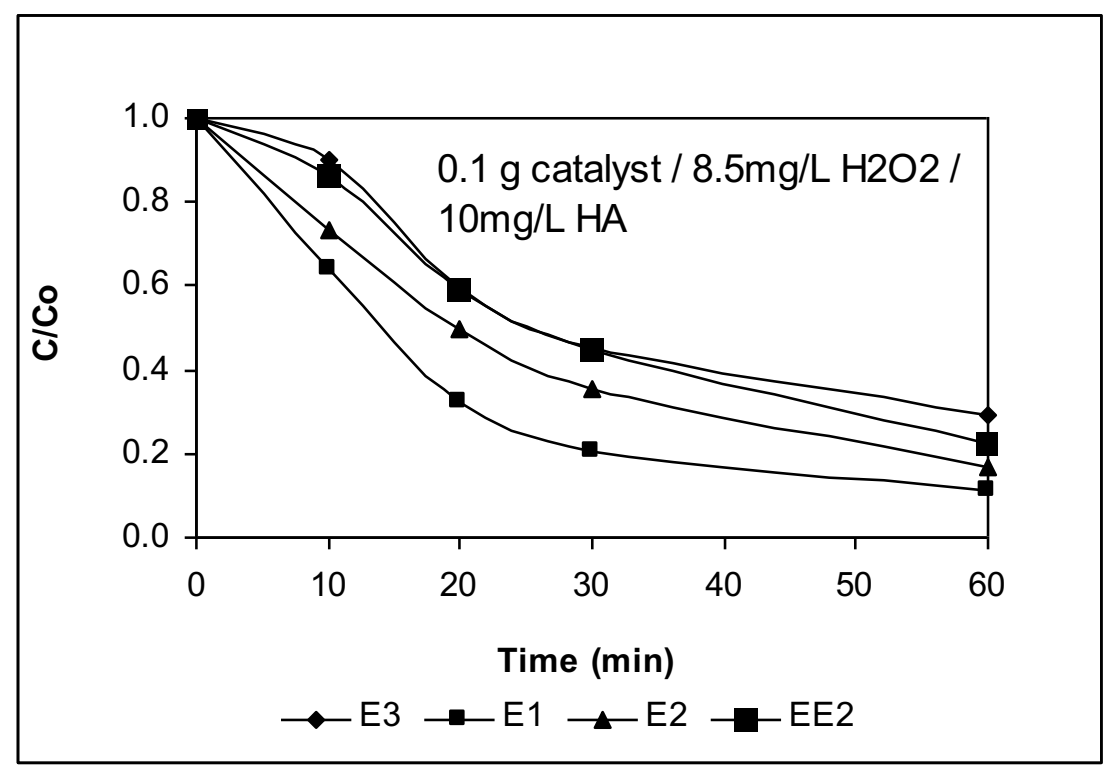

Figure 14: Effect of Humic Acid

\subsubsection{Effect of Radical Scavengers}

Wastewaters and natural water systems contain a variety of organic and inorganic contaminants that inhibit with oxidation reactions of $(\bullet \mathrm{OH}) \mathrm{Hydroxyl}$ radicals. The inorganic anions such as carbonate, bicarbonate and chloride are known as $\bullet \mathrm{OH}$ scavengers. Carbonate and bicarbonate ions are commonly exists in natural waters whereas chloride founds in high concentrations in some industrial wastewaters (such as; tannery and dye manufacturing wastewaters).

Carbonate, bicarbonate and chloride are known as hydroxyl radical scavengers; consequently, their excess concentration is expected to adversely affect AOP treatment efficiency. And also, the presence of $\mathrm{CO}_{3}{ }^{2-}$ and $\mathrm{HCO}_{3}{ }^{-}$in solution also interferes with $\mathrm{H}_{2} \mathrm{O}_{2}$ for $\mathrm{UV}$ light, decreasing the fraction it normally absorbs. This causes, in turn slows down the rate of hydroxyl radical generation. It was observable from the literature $[40,41] \mathrm{CO}_{3}{ }^{2-}$ is 45 times more reactive with - $\mathrm{OH}$ than $\mathrm{HCO}_{3}{ }^{-}$, therefore is more important retardant of the oxidation process. Considering this information we have just examined the effect of $\mathrm{CO}_{3}{ }^{2-}$ on the removal of estrogens mixtures. It was found that higher content of carbonate ions led to higher residuals of estrogens in the effluent. When $1,2.5,5$, and $10 \mathrm{mM} \mathrm{CO}_{3}{ }^{2-}$ were added to the solution, the removal efficiencies of estrogens decreased between $10 \%$ and $40 \%$.

\subsubsection{Degradation kinetics of estrogens}

The degradation of estrogens follows apparent first-order kinetics. Under UVC irradiation, the rate of degradation of estrogens in the mixture increased significantly. The faster degradation 
of the estrogens under UVC irradiation can be explained by their much stronger absorption of photons in the UVC region of the electromagnetic spectrum.

Table 3. Reaction rate constants of estrogens photooxidation in the presence of catalyst

\begin{tabular}{|l|l|l|l|l|}
\hline & E1 & E2 & EE2 & E3 \\
\hline $\mathrm{R}^{2}$ & 0.904 & 0.998 & 0.936 & 0.911 \\
\hline $\mathrm{k}_{1}\left(\mathrm{~min}^{-1}\right)$ & 0.048 & 0.041 & 0.064 & 0.022 \\
\hline
\end{tabular}

According to the first order reaction rate constants EE2 degradation was faster than the others EE2 $>$ E1 $>$ E2 $>$ E3 and also removal efficiency of EE2 (\%98) was higher than the other estrogens (Table 3). Similarly, in another work with immobilized $\mathrm{TiO}_{2}$ on titanium alloy in which mass-transfer limitations may have occurred, the degradation rate under UVA photolysis was found to be EE2 $>$ E1 $>$ E2 [5]. In another study, the treatment of EE2 using commercially available $\mathrm{TiO}_{2}$ suspensions (P25) with a conventional UV lamp was used. EE2 removals using P25 suspensions indicate first-order kinetics with rate constant corresponding to $62 \times 10^{-3}$ $1 / \mathrm{min}$ [43]. This results is almost the same rate with our study.

In the literature, comparing with UV treatment alone, UV and $\mathrm{H}_{2} \mathrm{O}_{2}(50 \mathrm{mg} / \mathrm{L})$ exhibited elevated transformation (a total degradation of $81 \%$ ) of the micropollutants [41]. After $30 \mathrm{~min}$ of $\mathrm{UV} / \mathrm{H}_{2} \mathrm{O}_{2}$, the transformation increased further up to $97 \%$. Fenton process $\left(5 \mathrm{mg} / \mathrm{L} \mathrm{Fe}{ }^{2+},{ }^{++} / 50\right.$ $\mathrm{mg} / \mathrm{L} \mathrm{H}_{2} \mathrm{O}_{2}$ ) achieved $31 \%$ degradation. It was able to completely eliminate only one of the micropollutants, norfloxacin, after $30 \mathrm{~min}$, and the concentrations of ten compounds were reduced by less than $15 \%$. When UV was applied to the Fenton process (under the same conditionsmentioned above), significantly increased global degradation (97\%) was observed. For the photo-Fenton process, either increased $\mathrm{H}_{2} \mathrm{O}_{2}$ dosage or extended reaction time was found to have positive impact on the global degradation [41]. In our study, we used far less than from the literature $\mathrm{H}_{2} \mathrm{O}_{2}$ and catalyst concentration.

\section{Conclusion and Comments}

One aim of this research was to develop a catalyst that did not produce an iron sludge from the photo-Fenton AOP and that was reproducible for use in wastewater treatment. The catalyst under UV irradiation were tested for their ability to photocatalytically degrade target estrogenic compounds. Experiments shows that the leached iron is a very minimal/limited amount, the small absorbance values measured and the fact that the catalyst was able to be re-used more than once led to the conclusion that a minimal amount of iron leaches. The same experiments were repeated three times in succession to determine the availability of the catalyst and effects on the catalyst yield were observed. Another aim was to discover the ability of the Poly(dimethylsiloxane) modified Nafion/Silica composite to catalyse a reaction to degrade estrogens. It was found that near $90 \%$ complete degradation of this environmentally significant pollutant was possible within 60 minutes. The study showed that the UV irradiated catalyst with $\mathrm{H}_{2} \mathrm{O}_{2}$ have the potential for treatment (removal) of these compounds. The data shows that the addition of only $0.1 \mathrm{~g}$ catalyst and $8.5 \mathrm{mg} / \mathrm{L} \mathrm{H}_{2} \mathrm{O}_{2}$ produced greatest conversion of estrogens within 60 minutes. 


\section{References}

[1] J. Sumpter, Xenoendocrine disrupters - environmental impacts, Elsevier Toxicology Letters, 102 (1998) 337-342.

[2] C. Tizaoui, S. Ben Fredj, L. Monser, Polyamide-6 for the removal and recovery of the estrogenic endocrine disruptors estrone, 17b-estradiol, 17a-ethinylestradiol and the oxidation product 2-hydroxyestradiol in water, Chemical Engineering Journal 328 (2017) 98-105.

[3] C. Miege, P. Bados, C. Brosse, Method validation for the analysis of estrogens (including conjugated compounds) in aqueous matrices., Trends in Analytical Chemistry, 28 (2009) 237-245.

[4] X. Li, H. Shi, K. Li, L. Zhang, Combined process of biofiltration and ozone oxidation as an advanced treatment process for wastewater reuse, Front. Environ. Sci. Eng. 9(6) (2015) 1076-1083.

[5] G. Li Puma, V. Puddu, H. K. Tsang, Photocatalytic oxidation of multicomponent mixtures of estrogens (estrone (E1), 17 $\beta$-estradiol (E2), 17 $\alpha$-ethynylestradiol (EE2) and estriol (E3)) under UVA and UVC radiation:Photon absorption, quantum ields and rate constants indepedent of photo absorption, Applied Catalysis B: Environmental, 99 (2010) 388-397.

[6] S. Esplugas, D. Bila, L. Krause, Ozonation and advanced oxidation technologies to remove endocrine disrupting chemicals and pharmaceuticals and personal care products in water effluents. Journal of Hazradous Materials, 149 (2007) 631-642.

[7] Chen TS, Chen TC, Yeh KJ, Chao HR, Liaw ET, Hsieh CY, Chen KC, Hsieh LT, Yeh YL, High estrogen concentrations in receiving river discharge from a concentrated livestock feedlot, Science of the Total Environment, 408 (2010) 3223-3230.

[8] Y. Koh, T. Chiu, A. Boobis, Treatment And Removal Strategies For Estogens From Wastewater, Environmental Technology, 293 (2008) 245-267.

[9] R. Gomes, M. Scrimshaw, J. Lester, Determination of endocrine disrupters in sewage treatment and receiving waters. Trends in Analytical Chemistry, 22 (2003) 697-707.

[10] D. Norris, J. Carr, Endocrine Disruption: Biological Bases for Health Effects in Wildlife and Humans. Oxford University Press, (2006) 202-204.

[11] L. Guillette, T. Gross, G. Masson, Developmental Abnormalities of the Gonad and Abnormal Sex Hormone Concentrations in Juvenile Alligators from Contaminated and Control Lakes in Florida, Environmental Health Perspective, 102 (2008), 680-688.

[12] G. Pojana, A. Gomiero, N. Jonkers, A. Marcomini, Natural and synthetic endocrine disrupting compounds (EDCs) in water, sediment and biota of a coastal lagoon. Environmental International, 33 (2007), 929-936.

[13] Commission, European. Endocrine Distrupter Research. European Commission Reseach \& Innovation. [Online] [Cited: 2 June 2012.] http://ec.europa.eu/research/endocrine/background_health_en.htmL\#top.

[14] A.J. Watkinson, E.J. Murby, S.D. Costanzo, Removal of antimicrobials using advanced wastewater treatment, Journal of Hazardous Materials, 192 (2011) 319-328.

[15] K. Ikehata, N.Naghashkar, M. El-Din, Degradation of Aqueous Pharmaceuticals by Ozonation and Advanced Oxidation Processes: A Review, Ozone: Science \& Engineering: The Journal of the International Ozone Association, 28 (2008) 353-414.

[16] T. Oppenlander, Photochemical Purification of Water and Air: Advanced Oxidation Processes (AOPs): Principles, Reaction Mechanisms, Reactor Concepts. s.l. : Wiley$\mathrm{VCH}, 2009$.

[17] A. Stasinakis, Use of selected advanced oxidation processes (aops) for wastewater treatment - a mini review, Global NEST Journal, 10 (2008), 376-385. 
[18] R. Zepp, B. Faust, J. Hoigne, Hydroxyl radical formation in aqueous reactions (pH 3-8) of iron(II) with hydrogen peroxide: the photo-Fenton reaction, Environmental Science Technology, 26(1992) 313-319.

[19] G. Ruppert, R. Bauer, G Heisler, The photo-Fenton reaction-an effective photochemical wastewater treatment process. Journal of Photochemistry and Photobiology, 73 (1993) 75-78.

[20] J. E. F. Moraes, F.H. Quina, C.A.O. Nascimento, D.N. Silva, O.C. Filho, Treatment of Saline Wastewater Contaminated with Hydrocarbons by the Photo-Fenton Process, Environmental Science \& Technology, 38 (2004), 1183-1187.

[21] J. Ramirez, L. Godinez, M. Mendez, Heterogeneous photo-electro-Fenton process using different iron supporting materials, Applied Electrochemistry, 40 (2010), 1729-1736.

[22] R. Hinze, M. Laufer, W. Holderich, The use of Nafion/silica composite catalysts for synthesis of fine chemicals, Elsevier Cataylsis Today, 140 (2008), 105-111.

[23] M. Harmer, W. Farneth, Q. Sun, High Surface Area Nafion Resin/Silica

Nanocomposites: A New Class of Solid Acid Catalyst, American Chemical Society, 118 (1996), 7708-7715.

[24] J. Fernandez, J. Bandara, A. Lopez, P. Buffat, J. Kiwi, Photoassisted Fenton Degradation of Nonbiodegradable Azo Dye (Orange II) in Fe-Free Solutions Mediated by Cation Transfer Membranes, American Chemical Society, 15 (1998) 185-192.

[25] M. Harmer, Q. Sun, A.J. Vega, W.F. Hölderich, Nafion resin silica nanocomposite solid acidcatalysts: Microstructure processing property correlations, Green Chemistry, 2 (2000), 7-14.

[26] Investigation of a direct methanol fuel cell based on a composite Nafion ${ }^{\circledR}$-silica electrolyte for high temperature operation. Antonucci, P, et al., et al. 1-4, October 1999, Elsevier Solid State Ionics, Vol. 125, pp. 431-437.

[27] M. Vohra, K. Tanaka, Photocatalytic degradation of aqueous pollutants using silicamodified $\mathrm{TiO}_{2}$, Water Research, 37 (2003), 3992-3996.

[28] S. Kim, Effects of pH During the Base Catalyzed Reaction of Two-Step Acid/Base Catalyzed Process on the Microstructures and Physical Properties of Poly(dimethylsiloxane) Modified Silica Xerogels. Journal of Sol-Gel Science and Technology, 27 (2008), 149-155.

[29] G. Beaucage, L. Guo, J. Hyeon-Lee, Kinetics of Morphological Development in Elastomer Modified Silica Xerogels, Rubber Chemistry and Technology, 72 (1999), 130-137.

[30] C. Yen, C. Lee, Y. Lin, Sol-gel derived sulfonated-silica/Nafion ${ }^{\circledR}$ composite membrane for direct methanol fuel cell, Elsevier Journal of Power Sources, 173 (2007), 36-44.

[31] Z. Barnes, Investigation of Histological Effects of 17- $\alpha$ Ethinylestradiol in Fathead Minnows (Pimephales promelas), Wartburg College. [Online] http://www.wartburg.edu/envstudies/Barnesetalposter.pdf.

[32] Spectrophotometric determination of iron. Chemistry. s.l. : Truman State University, 2008. Lab Manual.

[33] D. Harris, Experiment 9: Determination of Iron with 1,10-Phenanthroline . Quantitative Chemical Analysis. 6th. s.1. : Prentice Hall, (2003), 5, pp. 258-261, 407-422.

[34] M. Gmurek, M. Olak-Kucharczyk, S. Ledakowicz, Photochemical decomposition of endocrine disrupting compounds - A review, Chemical Engineering Journal 310 (2017), 437-456.

[35] S. Sarkar, S. Ali, L. Rehmann, G. Nakhla, M.B. Ray, Degradation of estrone in water and wastewater by various advanced oxidation processes, Journal of Hazardous Materials 278 (2014), 16-24. 
[36] G. Otriz de la Plata, O. Alfano, A. Cassano, The heterogeneous photo-Fenton reaction using goethite as catalyst, Water Science \& Technology, 61 (2010), 3109-3116.

[37] V.F. Fuhrmana, A. Tala, S. Arnonb, Why endocrine disrupting chemicals (EDCs) challenge traditional risk assessment and how to respond, Journal of Hazardous Materials 286 (2015), 589-611.

[38] N.Baycan Parilti, , C.S.U. Demirel, M. Bekbolet, Response surface methodological approach for the assessment of the photocatalytic degradation of NOM. Journal of Photochemistry and Photobiology A: Chemistry, 225 (2011), 26- 35.

[39] I. Gultekin, N.H. Ince, Degradation of Reactive Azo Dyes by UV/H2O2: Impact of Radical Scavengers. Journal of Environmental Science and Health, Part A: Toxic/Hazardous Substances and Environmental Engineering, 4 (2004) 1069-1081.

[40] Yi Yang, Yong Sik Ok, Ki-Hyun Kim, Eilhann E. Kwon, Yiu Fai Tsang, Occurrences and removal of pharmaceuticals and personal care products (PPCPs) in drinking water and water/sewage treatment plants: A review., Science of the Total Environment 596597 (2017) 303-320.

[41] Y. Luo, W. Guo, H.H. Ngo, L.D. Nghiem, F. Hai, J. Zhang, S. Liang, X.C. Wang, A review on the occurrence of micropollutants in the aquatic environment and their fate and removal during wastewater treatment, Science of the Total Environment 473-474 (2014) 619-641.

[42] D. Bila, A.F. Montalva, D.A. Azevedo, M. Dezotti, Estrogenic activity removal of 17bestradiol by ozonation and identification of by-products, Chemosphere 69 (2007) 736746.

[43] M. J. Arlosa, R. Liangb, M.M. Hatat-Fraileb, L.M. Bragga, N.Y. Zhoub, M.R. Servosa, S.A. Andrewsda, Photocatalytic decomposition of selected estrogens and theirestrogenic activity by UV-LED irradiated $\mathrm{TiO}_{2}$ immobilized on poroustitanium sheets via thermalchemical oxidation, Journal of Hazardous Materials 318 (2016), 541-550. 